\title{
Design and test of 2ZLX-2 transplanting machine for oil peony
}

\author{
Jiangtao $\mathrm{Ji}^{1,2}$, Qun Cheng ${ }^{1}$, Xin Jin ${ }^{1,2 *}$, Zhihong Zhang ${ }^{1}$, Xiaolin Xie ${ }^{1}$, Mingyong $\mathrm{Li}^{1}$ \\ (1. College of Agricultural Equipment Engineering, Henan University of Science and Technology, Luoyang, Henan 471003, China; \\ 2. Collaborative Innovation Center of Machinery Equipment Advanced Manufacturing of Henan Province, Luoyang, Henan 471003, China)
}

\begin{abstract}
In order to improve the quality of oil peony transplanting, based on the characteristics of peony seedlings and the transplanting effect, the transplanting process was analyzed. A peony seedling transplanting machine was designed, which was mainly composed of a chain-clamp type planting mechanism (clamp, transmission chain, sprocket), slideway, profiling wheels, trencher, the power transmission system and rack. Through the movement analysis of the planting mechanism and its operation process, its structural parameters were optimized. The effective length of the clamp was determined as $L_{1}=235 \mathrm{~mm}$, the adjustment range was $235-285 \mathrm{~mm}$, and the height of the planting trajectory was $H=340 \mathrm{~mm}$. Based on the physical characteristics and mechanical characteristics of the peony seedlings, the parameters of the slideway and the putter were determined. The effective length of the slideway was determined as $L_{2}=420 \mathrm{~cm}$, the width $T_{2}=105 \mathrm{~mm}$, the distance between the slideways $S=45 \mathrm{~mm}$. The initial angle difference of the putter was $\theta=13^{\circ}$, and the putter rotation angle $\beta=37^{\circ}$, putter height ratio $\varepsilon=2$. Based on the above parameters and design requirements, the radius of the planting sprocket $R_{1}=42 \mathrm{~mm}$, $R_{2}=80 \mathrm{~mm}$. "Feng Dan" peony seedlings were used as transplantation test objects. The results showed that: when the planting frequency was $60-75$ plants $/ \mathrm{min}$, the upright rate was $89.2 \%-92.8 \%$, the leakage rate was $0-0.28 \%$, the injury rate of seedlings was 0 , and the qualified rate of planting depth was $91.7 \%-95.3 \%$, the variation coefficient of plant spacing was $0.25 \%-0.54 \%$. This machine can effectively improve the quality and efficiency of transplanting, meeting the requirements of mechanical design and production needs.
\end{abstract}

Keywords: peony transplanting, planting mechanism, oil peony, peony seedlings, parameter design, test analysis DOI: $10.25165 /$ j.ijabe.20201304.5695

Citation: Ji J T, Cheng Q, Jin X, Zhang Z H, Xie X L, Li M Y. Design and test of 2ZLX-2 transplanting machine for oil peony. Int J Agric \& Biol Eng, 2020; 13(4): 61-69.

\section{Introduction}

Oil peony is an emerging woody oil crop, which has the advantages of low cost, high output, and high quality. It is a unique plant resource in China and has an extremely high economic value. Peony products include peony oil, peony flower tea, peony flower wine, peony dried pollen, peony petals, and medicinal materials. In particular, peony oil has a polyunsaturated fatty acid-linolenic acid content of more than $40 \%$, which is 40 times that of olive oil. Peony oil is the best edible oil in the world, known as "liquid gold" [1-3]. In recent years, the area and yield of major oil crops in China have shown a downward trend. With the development of China's economy and the acceleration of urbanization, China's per capita consumption of vegetable oil has maintained an upward trend with GDP growth. The contradiction between the supply and demand of edible vegetable oil in China is increasing. Due to the lack of systematic research on morphological parameters and transplanting effects of peony

\section{Received date: 2020-01-17 Accepted date: 2020-04-2}

Biographies: Jiangtao Ji, $\mathrm{PhD}$, Professor, research interests: agricultural utility robot technology, Email: jjt0907@163.com; Qun Cheng, Master candidate, research interests: precision agriculture technology, Email: 18437923892@ 163.com; Zhihong Zhang, Professor, research interests: mechanization of oil crops, Email: lyzzh36@163.com; Xiaolin Xie, PhD, Lecturer, research interests: agricultural machinery walking control, Email: xiexiaolin@haust.edu.cn; Mingyong Li, PhD candidate, research interests: agricultural information and intelligent machine, Email: mingyonglee@163.com.

*Corresponding author: Xin Jin, PhD, Associate Professor, research interests: agricultural utility robot technology. Henan University of Science and Technology, Luoyang 471003, China. Tel: +86-379-64877817, Email: jx.771@163.com. seedlings, China's current peony planting mainly relies on manual work, which is labor intensive, costly and inefficient ${ }^{[4-7]}$. This severely restricts the development of the peony industry. In the industry chain of peony products, the transplantation of its seedlings is the main problem currently facing. It is also an important link to reduce the cost of peony products. Peony seedlings have multiple roots and irregular distribution. The particularity of seedling morphology increases the difficulty of mechanization for peony transplanting. Therefore, the development of a peony transplanting machine should use a semi-automatic transplanting machine as a transition and gradually realize fully automatic transplanting operation. At present, due to workers' feed rate, the efficiency of semi-automatic transplanters is low (about 40 plants/min) ${ }^{[8-10]}$. The planting mechanism was a key component of the transplanter and directly affects a number of operating indexes of the transplanter. According to the type of planting mechanism, it can be divided into clamp type, hanging basket type, flexible disc type, duct type and reciprocating transplanter ${ }^{[11-14]}$. Therefore, it is necessary to optimize the design of the peony transplanting machine and its key components based on the study of peony seedling characteristics and transplanting effects.

The working object of this transplanter was peony seedlings. During the transplanting operation, the peony seedlings were manually taken out from the seedling box by hand and then placed into clamps in turn. When the seedlings were transported to the bottom end via a chain drive, the clamps automatically release the seedlings for planting. The planting process requires low damage to the seedlings and orderly human-machine action, which helps improve the quality and efficiency of planting ${ }^{[15-17]}$. Foreign research on transplanting machinery was earlier. The technical 
equipment was relatively mature, and various models of transplanters have been developed. More typical were the automatic transplanters developed by American Renaldo company, the Futura series automatic transplanters designed by Ferrari of Italy, the Mark 5 automatic transplanters produced by Pearson of the United Kingdom, Japanese Yanmar PF2R automatic transplanter, and the large automatic transplanters designed by Williames of Australia. However, the above transplanters still have problems such as large size, high price, and complicated structure. The scope of popularization and application in China is very small $^{[18-20]}$.

Domestic research on transplanting machinery started later. In order to improve the operation quality of transplanters, domestic scholars have conducted research and achieved many results. A semi-automatic transplanting machine for compressed substrate-type potted seedlings was designed by Han et al. ${ }^{[21]}$, and the transplanting qualification rate reached $90.62 \%$. A fully automatic transplanter for dryland potted vegetable seedlings was developed by Wang et al. ${ }^{[22]}$ with a planting pass rate of $91.1 \%$. A fully automatic film transplanting machine for vegetable plug tray seedling was developed by $\mathrm{Li}$ et al. ${ }^{[23]}$ It can complete multiple operations at one time, and the pass rate of transplantation reaches 93.4\%. Aiming at the seedling transplanting operation, a lightweight simple automatic transplanting machine was designed by Han et al. ${ }^{[24]}$ The transplantation success rate was $90.70 \%$ as measured by transplantation tests. A substrate vegetable transplanter with a planting frequency of 57 plants/min was designed by Cui et al. ${ }^{[25]}$

Oil peony has great development prospects and market demand. Improving the efficiency and quality of oil peony transplanting has become an urgent problem. Therefore, a semi-automatic transplanting machine for peony seedlings was developed based on the physical characteristics and transplanting effects of peony seedlings. Its key parameters and core components were designed. In order to verify its transplanting performance, field experiments for peony seedlings were carried out under different planting frequencies.

\section{Study on characteristics of peony seedlings}

A more typical peony seedling was selected as the test subject for the seedling. The "Feng Dan" variety has a large amount of seed, high oil yield, wide adaptability and strong growth potential. Generally, Compared with 1-2-year-old peony seedlings, 3 -year-old peony seedlings have more advantages. Therefore, the 3-year-old "Feng Dan" peony seedlings were selected as test objects. The seedling moisture content was between $38.4 \%$ and $47.6 \%$. Peony seedlings grew vigorously and the root system was developed. Peony seedlings were shown in Figure 1.

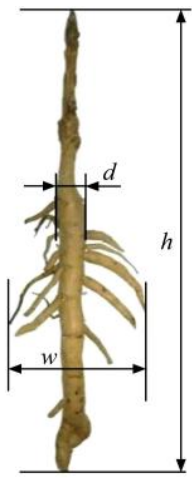

Figure 1 Peony seedlings
In order to provide theoretical reference for the design of peony transplanter, in this paper, 60 three-year-old peony seedlings were randomly selected and statistically analyzed for their physical and mechanical characteristics. At the same time, the physical and mechanical characteristics of peony seedlings were tested. The test results were shown in Table 1 . Where $w$ was the seedling width, $h$ was the seedling height. $\quad w$ and $h$ were measured with a ruler with an accuracy of $1 \mathrm{~mm}$. $d$ was the stem diameter. It was measured with the vernier caliper with an accuracy of $0.05 \mathrm{~mm}$ from the seedling root.
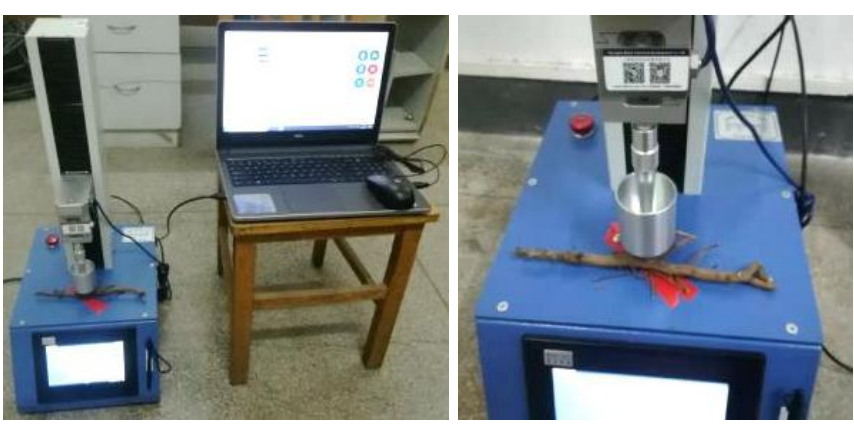

Figure 2 Mechanical properties test of peony seedlings

Table 1 Statistical results of peony seedling characteristic parameters

\begin{tabular}{clccc}
\hline \multicolumn{2}{c}{ Physical property statistics } & Max & Min & Average \\
\hline \multirow{3}{*}{$\begin{array}{c}\text { Morphological } \\
\text { properties }\end{array}$} & Width/mm & 47.2 & 31.6 & 38.5 \\
& Stem diameter/mm & 255.1 & 224.8 & 244.8 \\
& Weight/g & 15.50 & 12.10 & 13.50 \\
\hline Mechanical & Pressure resistance/N & 0.76 & 0.52 & 0.60 \\
properties & Displacement/mm & 1.38 & 1.06 & 1.25 \\
\hline
\end{tabular}

It can be concluded from the experiments that the morphological characteristics of the peony seedlings were as follows: the average height was $244.8 \mathrm{~mm}$, the average seedling width was $38.5 \mathrm{~mm}$, and the average stem diameter was $13.5 \mathrm{~mm}$. Its mechanical properties were represented by an average compressive strength of $0.60 \mathrm{~N}$ and an average compression displacement of $1.25 \mathrm{~mm}$.

\section{Overall design of transplanting machine}

\subsection{Overall structural design}

2ZLX-2 transplanting machine for peony seedlings was mainly composed of a chain-clamp type planter (clamp, putter, rubber pad), planting chain, planting slideway, trencher, transmission mechanism, seedling box, soil-covered suppression wheel, profiling wheel and rack assembly, etc. The planter consisted of clamps, push rods and rubber pads, and was evenly mounted on the planting chain. It can transport seedlings and perform planting operations. The soil compaction wheel consisted of planting disc, grip device, and removal device. The soil-covering wheels were installed symmetrically on both sides of the transplanter at an angle of $15^{\circ}$ to the vertical. The planting unit adopted the hook structure, which was convenient for adjusting the plant spacing and the number of planting rows. The seedling boxes were installed on both sides of the planter. The seedling box port was set to a slope of $145^{\circ}$ to prevent the seedlings from falling off during the operation. Profiling wheels were installed on both sides of the transplanter to stabilize the planting depth of the transplanter.

The main technical parameters of the machine for peony seedlings were shown in Table 2 . 
Table 2 Main technical parameters

\begin{tabular}{lc}
\hline \multicolumn{1}{c}{ Items } & Parameters \\
\hline Structure type & Three-point suspension \\
Dimensions (length $\times$ width $\times$ height $) / \mathrm{mm}$ & $1900 \times 1600 \times 1200$ \\
Supporting power $/ \mathrm{kW}$ & $14.7-36.8$ \\
Hook type & Traction type \\
Machine quality $/ \mathrm{kg}$ & 400 \\
Working width $/ \mathrm{m}$ & $0.5-1.2$ \\
Number of work rows & $2-3$ \\
Planter type & chain-clamp type \\
Work rows spacing $/ \mathrm{mm}$ & $500-1000$ \\
Plant spacing $/ \mathrm{mm}$ & $190-800$ \\
Planting depth $/ \mathrm{mm}$ & $40-100$ \\
Operating speed $/ \mathrm{mm} \cdot \mathrm{s}^{-1}$ & $150-550$ \\
Suitable seedling & $120-200 \mathrm{~mm}$ best \\
Working efficiency $/ \mathrm{hm}^{2} \cdot \mathrm{h}^{-1}$ & $0.1-0.16$ \\
Number of operators $($ including tractor hand) & 3 \\
\hline
\end{tabular}

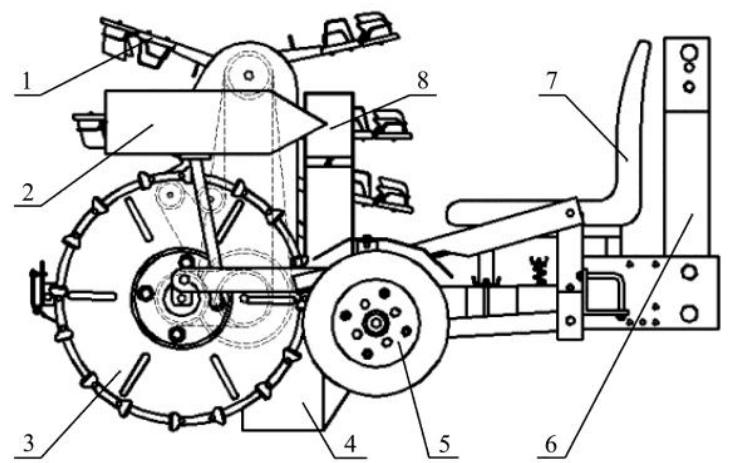

a. Overall structure diagram

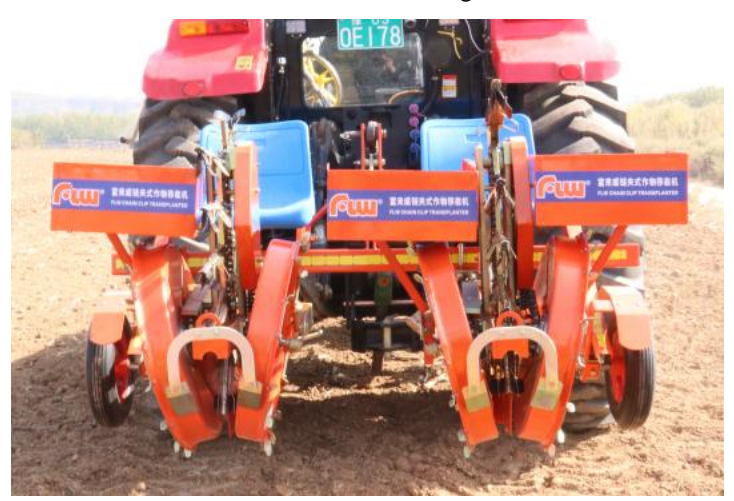

b. Physical prototype

1. Clamp 2. Seedling box 3. Soil compaction wheel 4. Trencher

5. Profiling wheel 6. Rack 7. Seat 8. Slideway

Figure 3 Structural sketch of 2ZLX-2 transplanter for oil peony seedlings
The transplanting machine for peony seedlings was developed by Henan University of Science and Technology in cooperation with Nantong Fulaiwei Agricultural Equipment Co., Ltd. (Fulaiwei). Fulaiwei Agricultural Equipment Co., Ltd. completed the manufacture of prototypes. Its overall structure is shown in Figure $3 \mathrm{~b}$.

\subsection{Working principle}

Two operators sit side by side at the front of the transplanter. The 3 seedling boxes were evenly arranged around the transplanter. This helps make it easier to catch seedlings by hand. Before transplanting, the peony seedlings were packed in 3 seedling boxes with the roots facing the operator. During the transplanting process, the machine walks to ditch and transplant, and the machine stops to stop transplanting. After the speed of the standby device was stable, the operators smoothly caught the peony seedlings from the seedling box and fed them into the clamps in turn. The roots' direction of the seedling was required to be the same as the machine's forward direction. And the root of the seedling was slightly beyond the end of the clamp. The clamp was driven by the transmission chain to rotate and move down. When the clamp enters the slideway, the putter rotated a certain angle to tighten the rubber pad to realize the movement of clamping the seedling. When the clamp moves to the end of the slideway, the putter rotated in the opposite direction to reset the rubber pad. Peony seedlings fell straight into the groove. And the planting operation was completed by the falling soil and the soil compaction wheel. Reciprocate like this to achieve semi-automatic transplanting.

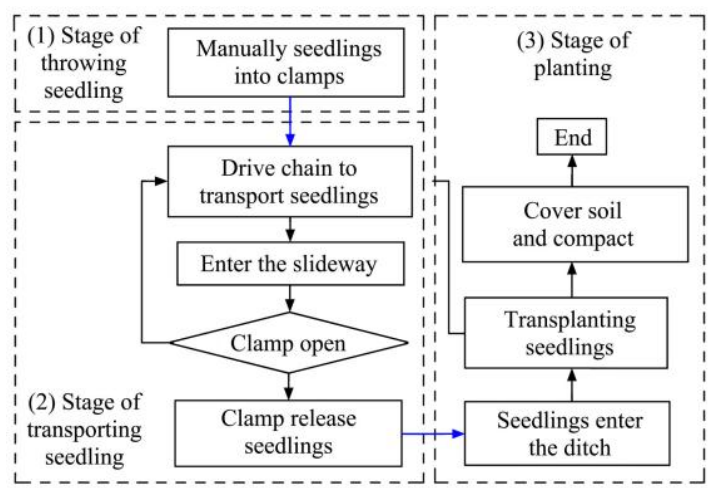

Figure 4 Working principle of transplanter for peony seedlings

The number of rows of the transplanter was adjustable. This machine was suitable for transplanting on flat ground or ridge. It can realize seedling transporting, ditching, planting and soil compaction at one time. Its design operation rows spacing was $500-1000 \mathrm{~mm}$, and the plant spacing can be adjusted between $27-80 \mathrm{~cm}$. The number of sprocket teeth and their corresponding plant spacing are shown in Table 3.

Table 3 Plant spacing regulation table

\begin{tabular}{|c|c|c|c|c|c|c|c|c|c|c|c|c|}
\hline Transmission sprocket 2 & & & & & & & & & & & & \\
\hline Transmission sprocket 1 & 24 & 22 & 20 & 18 & 16 & 15 & 20 & 18 & 17 & 16 & 14 & 12 \\
\hline Plant spacing/cm & 27 & 32 & 35 & 38 & 42 & 44 & 48 & 54 & 57 & 60 & 70 & 80 \\
\hline
\end{tabular}

\subsection{Power layout}

A tractor powered the peony seedling transplanter, its power transmission system as shown in Figure 5. It was connected by a three-point suspension so as to traction the transplanter. The tractor engine power was $14.7-36.8 \mathrm{~kW}$. The tractor engine power was transmitted to the soil-covered suppression wheels on both sides of the planter via the walking clutch. Then, the power was transmitted to the drive sprocket. One end of the drive chain rotates coaxially with the earth-covering wheel, and the other end rotates coaxially with one end of the transmission chain. The other end of the transmission chain rotated coaxially with the upper end of the planting chain. This transmitted power to the planting chain. The clamp-type planters were evenly distributed and fixed on the planting chain. Thus, the planting chain was driven to 
rotate up and down, and the seedlings were transported and planted. The innovation of this article was that the power was directly connected from the cover wheel. Therefore, the power transmission system fluency of the transplanter was improved, and the power loss was reduced.

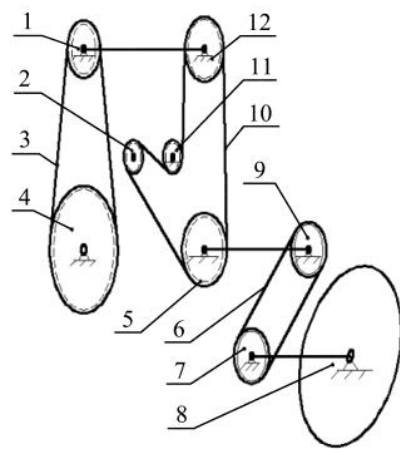

a. Transmission principle

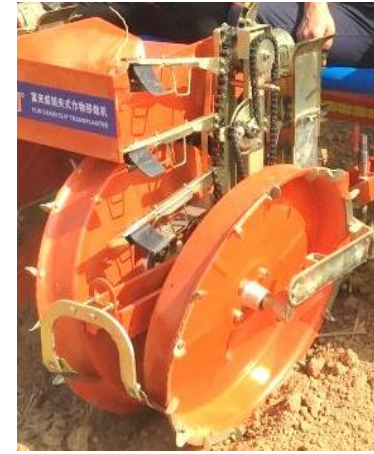

b. Physical structure
1, 4. Planting sprockets 2, 11. Adjustment sprockets 3. Planting chain

5, 12. Transmission sprockets 6. Drive chain 7, 9. Driving sprockets

8. Earth-covering suppression wheel 10. Transmission chain

Figure 5 Power transmission system of the peony seedling transplanter

\section{Design of key components}

The planting mechanism can directly affect the quality of transplanting. It was the core component of a semi-automatic transplanter. Therefore, it is critical to improving the quality of transplanting operations through reasonable design.

\subsection{Requirements for planting mechanism design}

Where, at point a, the planter entered the seedling ditch. At point $\mathrm{b}$, the clamps released the peony seedlings. Point $\mathrm{c}$ was the planting point, and planting was performed at this time. At point $\mathrm{d}$, the planter left the seedling ditch.

Semi-automatic transplanting machine for oil peony takes the seedling manually and feeds it to the planting mechanism. The planter clamps the seedlings when entering the slideway. When leaving the slideways, the clamps were released to release the seedlings. The seedlings fall into the seedling ditch opened by the opener. The planting was completed by the planter and the soil compaction wheel. The trajectory of the planter as shown in Figure 6. By analyzing the motion trajectory of the existing planting mechanism, in order to achieve rapid and accurate transplanting of peony seedlings, the motion trajectory of the planter should meet the following requirements:

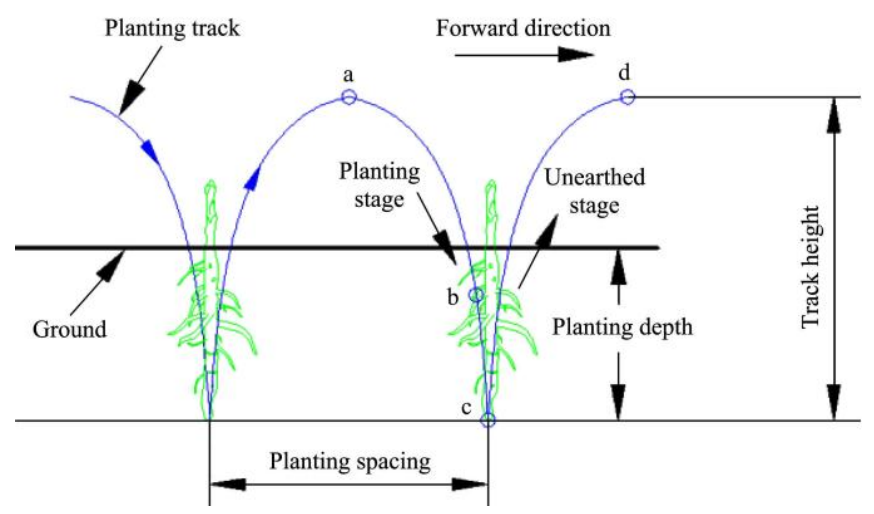

Figure 6 The trajectory of planter movement

1) When the planter is vertical, it is the planting point. The planter should release seedlings and plant at the planting point to increase the rate of seedlings transplanted.
2) Theoretically, the planting trajectory is required to be cycloid. The absolute speed of the clamps and seedlings at the planting point should be 0 to achieve zero-speed planting. This can improve transplanting quality.

3) The rotation angle of the planter before and after entering the slideway is $90^{\circ}$. During this period, the movement of the planter holding the seedlings should not fall.

4) The movement trajectory of the planter entering and exiting the seedling ditch should be as straight as possible.

5) Be sure to keep the roots of peony seedlings stretched after planting.

\subsection{Mechanism structure and working principle}

\subsubsection{Structure of planting mechanism}

The machine used a chain-clamp type planter to transplant peony seedlings. Its structure diagram was shown in Figure 7. The planting mechanism was mainly composed of a clamp-type planter (clamp, putter, rubber pad), planting chain, planting sprocket, and slideways. The planter was evenly fixed on the planting chain. The upper and lower planting sprocket wheels were fixedly connected to the rack. The planting slideways were fixed in front of the planter. The slideway can put the putter into proper pressure.

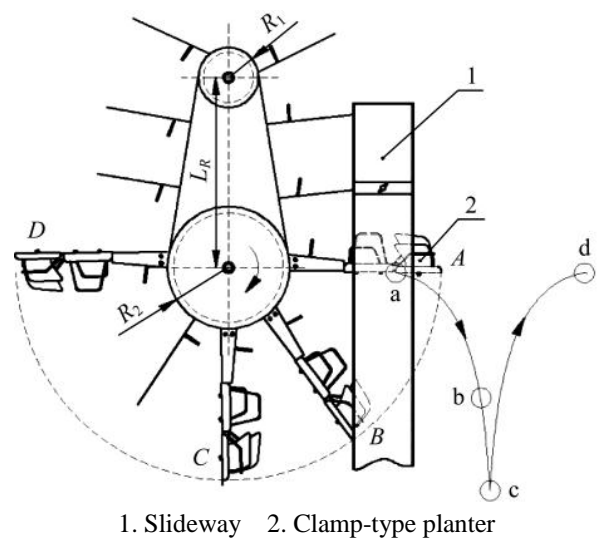

Figure 7 Schematic diagram of planting mechanism

\subsubsection{Working principle of planting mechanism}

The planters were evenly installed on the transport chain by the hinge. Fixing the bolts to different positions can change the length of the planter. During operation, the drive chain connected the power to the planting chain, which drives the planting sprocket and the clamp-type planter to rotate. The two planting sprockets rotated synchronously. The planter then entered between the two slideways. Under the pressure of the slideways, the putter makes the rubber pad clamp the seedlings to prevent them from falling. The movement of the planter from the $A$ position to the $B$ position corresponds to the trajectory curve from point a to point $b$. The planter moved from position $B$ to position $C$ on the corresponding trajectory curve from point $\mathrm{b}$ to $\mathrm{c}$. The movement of the planter from the $C$ position to the $D$ position corresponds to the trajectory curve from point $\mathrm{c}$ to point $\mathrm{d}$.

When the clamps move to position $A$, the planter started to enter the opened seedling ditch. When moving to point $B$, the clamps left the slideways and the putter loosen. When the movement reaches point $C$, the clamp was opened and the seedlings fell into the seedling ditch. The soil was then compacted by the compaction wheel so that the roots were in close contact with the soil. It was good for heat preservation and moisture retention. When moving to point $D$, the planter has finished planting and started to leave the seedling ditch. Perform the cycle operation like this. 


\section{Key parameter design of core components}

\subsection{Parameter design of planter}

The planter was the core component of the transplanter. This machine used the chain clamp-type planter, which is mainly composed of clamps, putter, rubber pads and position-limiting device. The clamp was hinged with the planting chain, and the other parts were connected with the clamp using screw fasteners. In this way, seedlings can be transported, released and planted.

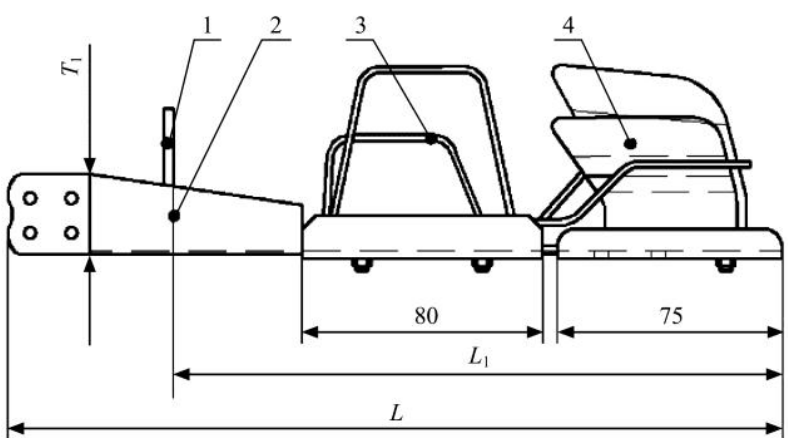

a. Planter parameter design

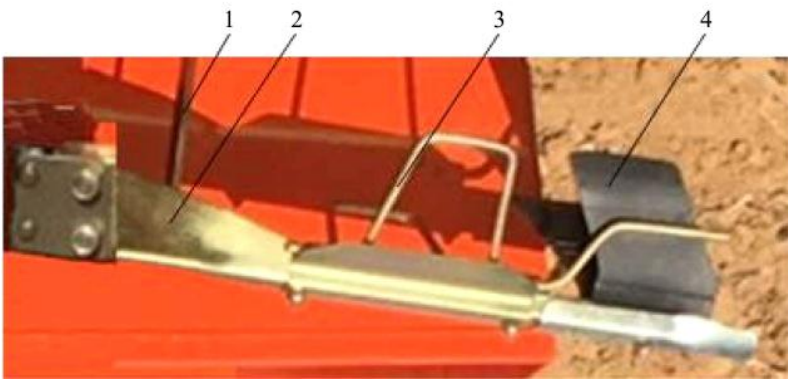

b. Physical picture of planter

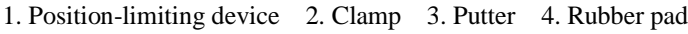

Figure 8 Structure and parameters of the oil peony planter

The design criteria of the planter were as follows: in the case of no interference with the slideways and no damage to the seedlings, the angle difference between the clamping and loosening of the putter was as small as possible. This can prevent damage to seedlings during seedling transporting. At the same time, this can reduce the wear of the putter and extend the service life. The whole body was made of stainless steel. Its front end was hinged with the chain and fixed by bolts. The front end was a trapezoidal structure with a width of $T_{1}=30 \mathrm{~mm}$, which increases the strength of the part. In order to ensure the consistency of the feeding position, a position-limiting device was set, and its height was $65 \mathrm{~mm}$. Based on the physical characteristics of the peony seedlings, in order to meet the design requirements of the seedlings slightly beyond the end of the clamp after feeding, the total length of the clamp was determined to be $L=265 \mathrm{~mm}$, the effective length was $L_{1}=235 \mathrm{~mm}$, and the radii of the planting sprocket were $R_{1}=$ $42 \mathrm{~mm}$ and $R_{2}=80 \mathrm{~mm}$. The distance between the sprockets was $L_{R}=460 \mathrm{~mm}$. The effective length of the planter can be adjusted with the length of seedlings between 235-285 mm. Specifically, the length was adjusted by adjusting different fixed positions.

\subsection{Parameter design of putter and slideway}

If the clamping force is too small, the seedlings will fall easily, resulting in leakage of seedlings and affecting the quality of transplanting. If the clamping force is too large, it is easy to damage the peony seedlings, causing problems such as seedling injuries and lodging. In order to avoid seedlings falling or damaging the seedlings, it is necessary to design the putter and slideway to meet the agronomic requirements and mechanical design.

When the planter enters the slideway, the squeeze of the sidewall pushed the putter to rotate. The rear end of the putter squeezed the rubber pad so that the rubber pads on both sides form pressure $F_{1}$ and $F_{2}$ on the seedling. At the same time, the seedlings had a tendency to fall under the effect of their own gravity. The force was balanced by the static friction forces $f_{1}$ and $f_{2}$ provided by the rubber pad. $F_{0}$ was the downward force. $S_{1}$ $\left(S_{2}\right)$ was the force arms acting on the rear end of the putter. The stress analysis of peony seedlings was shown in Figure 9.

$$
\begin{gathered}
F_{0}=f_{1}+f_{2} \\
f_{1}=\mu F_{1} \\
f_{2}=\mu F_{2} \\
F_{0}=\operatorname{mgco} \alpha \mathrm{s}
\end{gathered}
$$

where, the static friction force $f_{1}=f_{2} ; m$ is the seedling's mass; $g$ is the acceleration due to gravity; $\alpha$ is the inclination of the planter.

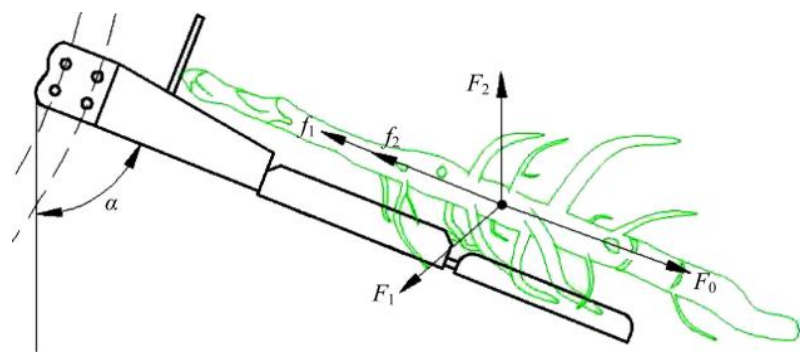

Figure 9 The force analysis for peony seedlings

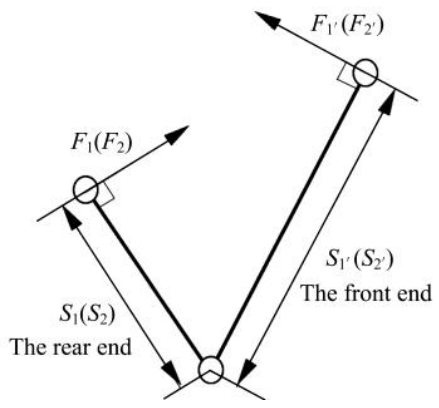

Figure 10 Putter torque analysis

where, $F_{1^{\prime}}$ and $F_{2^{\prime}}$ are the forces acting on the front end of the push rod; $S_{1^{\prime}}\left(S_{2^{\prime}}\right)$ is the force arms acting on the front end of the putter. According to the principle of torque balance:

$$
F_{1}=F_{2}=\frac{S_{1^{\prime}}}{S_{1}} F_{1^{\prime}}=\frac{S_{2^{\prime}}}{S_{2}} F_{2^{\prime}}
$$

Define $\varepsilon=\frac{S_{1^{\prime}}}{S_{1}}=\frac{S_{2^{\prime}}}{S_{2}}$, thus,

$$
F_{1}=F_{2}=\varepsilon F_{1}{ }^{\prime}=\varepsilon F_{2}{ }^{\prime}
$$

where, $\varepsilon$ is the ratio of the arms; $F_{1}{ }^{\prime}$ and $F_{2}{ }^{\prime}$ are determined by the distance $S$ of the slideways. Comprehensive Equations (1)-(5):

$$
\operatorname{mg} \cos \alpha=2 \mu \varepsilon F_{1}^{\prime}
$$

The design requires that the clamp planter can't drop seedlings before exiting the slideway. The maximum angle of inclination was when the clamp was out of the slideways. Since the distance between the slideways was constant, the pressures $F_{1}{ }^{\prime}$ and $F_{2}{ }^{\prime}$ were constant. The friction coefficient of the rubber pad was also constant. It can be seen that the key factor that determines whether the seedling movement state is stable was the ratio of the force arms $\varepsilon$ and the inclination angle $\alpha$ of the planter.

The $P$ and $P^{\prime}$ points were the two extreme positions of the putter. When moving from point $P$ to point $P^{\prime}$, the planter was clamped and vice versa. Based on the above parameters and design requirements, the initial angle difference between the two 
ends of the putter was $\theta=13^{\circ}$. The angle between the two extreme positions was $\beta=37^{\circ}$. The ratio of the pusher arm was $\varepsilon=2$.

The distance between the two slideways was determined as $S=35 \mathrm{~mm}$, the total length of the slideways was $L_{2^{\prime}}=500 \mathrm{~mm}$, the width was $T_{2}=105 \mathrm{~mm}$, the effective length was $L_{2}=420 \mathrm{~mm}$, the entrance radius of the slideway was $R_{0}=80 \mathrm{~mm}$, and the height of the planting track was $H=340 \mathrm{~mm}$.

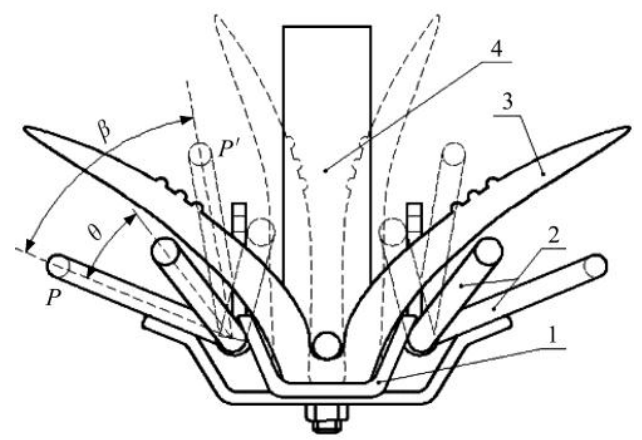

1. Clamp 2. Putter 3. Rubber pad 4. Position-limiting device Figure 11 Limit positions of putter

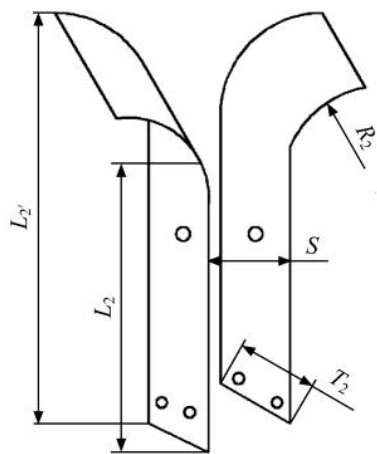

Figure 12 Design of slideway parameters

\section{Field test}

\subsection{Test conditions}

In order to verify the transplanting performance of the peony transplanter, an outdoor field test was carried out at an outdoor temperature of $23^{\circ} \mathrm{C}$, air humidity of $27 \%$, a wind speed of $3.5 \mathrm{~m} / \mathrm{s}$, and a soil moisture content of about $12.5 \%$. The test field was rotated and weeded without large soil blocks. For oil peony planting, high-dry and sunny land should be selected. Sandy loam was better and the terrain was flat. The soil was required to be loose and breathable, and the drainage performance was good. Its suitable $\mathrm{pH}$ range was 6.5-8.0.

Fulaiwei Company and Henan University of Science and Technology's Agricultural Equipment Engineering College jointly tested the transplanting prototype for peony seedlings and conducted field transplanting experiments. The field planting performance test was conducted in Yibin District, Luoyang City, Henan Province. And the transplanting test site is shown in Figure 13.

\subsection{Test materials}

The 3-year-old seedlings have the advantages of early flowering and fruiting, high survival rate, and low field management costs. It was the first choice seedlings for peony transplanting. The moisture content of peony seedlings ranged from $38.4 \%$ to $47.6 \%$. It had strong growth and a developed root system. Field test should be carried out as soon as possible after the seedlings were purchased. This can minimize the impact on the activity of peony seedlings. The test tractor model was
Boma-424. The measuring instruments used in the test were multi-angle protractors, photoelectric digital tachometers, electronic stopwatches, soil moisture meters, and so on.

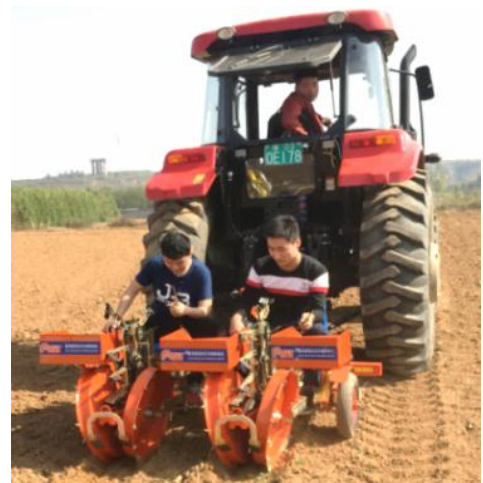

Figure 13 Transplanting test site

\subsection{Test indexes}

Upright rate, leakage rate and injury rate of seedlings were important evaluation indexes to measure the quality of the transplanting machine. They have a great impact on the later growth of seedlings. Qualification rate of planting depth and plant spacing variation coefficient were important indexes for planting accuracy of transplanting machines. They can directly affect the effective productivity of the transplanter. The specific calculation formulas of the test indexes were as follows:

$$
\begin{gathered}
L=\left(1-\frac{N_{D F}}{N}\right) \times 100 \% \\
M=\frac{N_{L Z}}{N} \times 100 \% \\
W=\frac{N_{S M}}{N} \times 100 \% \\
H=\frac{N_{h}}{N} \times 100 \% \\
C V_{x}=\frac{S_{x}}{\bar{X}} \times 100 \%
\end{gathered}
$$

where, $L$ is the rate of standing seedlings, $\% ; M$ is the rate of missing plants, $\% ; W$ is the rate of injured seedlings, $\% ; H$ is the qualified rate of planting depth, $\% ; C V x$ is the variation coefficient of the plant spacing, $\% ; N_{D F}$ is the number of lodging plants, plant; $N_{L Z}$ is the number of missing plants; $N_{S M}$ is the number of injured seedlings; $N_{h}$ is the number of seedlings with good planting depth; $S x$ is the standard deviation of the plant spacing; $\bar{X}$ is the average of the plant spacing; $N$ is the total number of seedlings.

It can be verified according to the operation quality regulations of the transplanter.

\subsection{Test method}

Before the test, the transplanter should be strictly inspected to ensure that the rotating parts and the adjusting mechanism are flexible and reliable. The transplanter should be installed firmly and reliably. There should be no abnormal noise, so as not to affect the test results due to poor machine adjustment. Adjust the operating parameters of each mechanism. Specifically, adjust the frame of the transplanter to be parallel to the ground. Adjust the ditch depth of the ship-type opener to $20 \mathrm{~cm}$. Check whether the inclination angle of the soil compaction wheel is within $\pm 15^{\circ}$. In order to obtain a theoretical plant spacing of $320 \mathrm{~mm}$, the number of teeth matched with the double sprocket and the drive sprocket should be changed to 14 and 22, respectively. The planting depth was adjusted by adjusting the trenching depth of the trencher. 
Then, place the peony seedlings neatly and orderly in the seedling boxes. The roots of the seedlings were directed towards the operator for manual seedling placement. Pick peony seedlings manually and place them in the clamp. Adjust the working speed of the transplanter with a digital tachometer. The forward speeds were adjusted to $320 \mathrm{~mm} / \mathrm{s}, 400 \mathrm{~mm} / \mathrm{s}$, and $480 \mathrm{~mm} / \mathrm{s}$, and the corresponding planting frequencies were $60 \mathrm{plants} / \mathrm{min}$, 75 plants/min, and 90 plants/min.

In order to ensure that the test results are accurate and reliable, the transplanter needs to be adjusted to the specified speed and the speed is stable before the test. Select robust peony seedlings for testing. The 10 seedlings (one working cycle) near the start and stop stages were not counted. Take $25.6 \mathrm{~m}$ as a measurement area and set a benchmark. Three test areas were taken at each planting frequency, and the test areas cannot be repeated. Three experiments were performed at each planting frequency for a total of 9 groups. Every time transplantation was completed in a survey area, the planting status should be checked. The planting status of each seedling must not be repeated. Record the test data and bring it into the above formula for statistics.

\section{Results and discussion}

\subsection{Test results}

The test results are shown in Table 4.

Table 4 Test results of main performance indexes

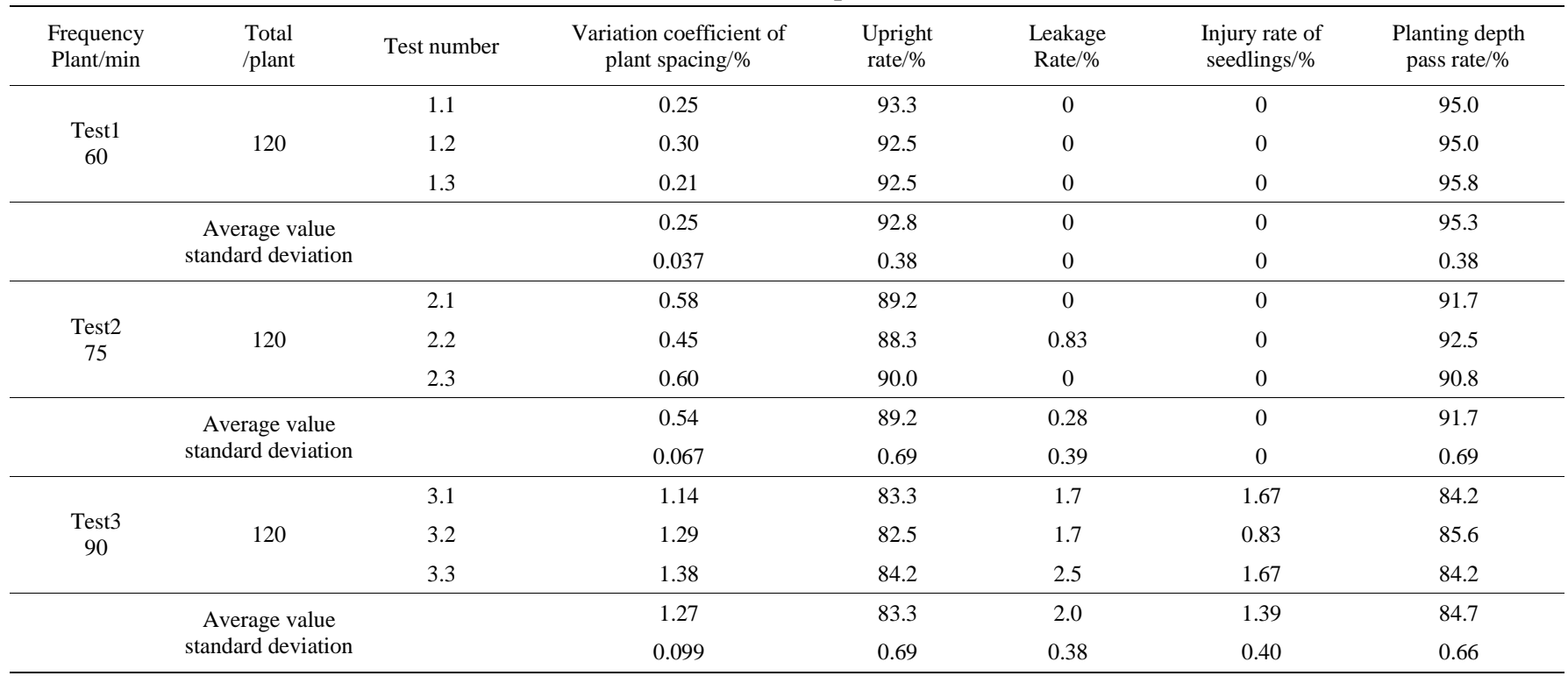

Observation of the test process and analysis of the data in Table 4 showed that the machine runs smoothly and can better meet the requirements of oil peony transplanting operations. The test results showed that: under this test condition, the upright rate and qualification rate of planting depth reached the highest at 60 plants/min, which were $92.8 \%$ and $95.3 \%$ respectively. The lowest was at 90 plants/min, which were $83.3 \%$ and $84.7 \%$ respectively. The leakage rate, the injury rate of seedlings and variation coefficient of plant spacing reached the highest at 90 plants/min, which were $2 \%, 1.39 \%$ and $1.27 \%$, and reached the lowest at 60 plants/min, which were 0,0 , and $0.25 \%$. The test results showed that the transplanting machine meets the design requirements for peony transplanting.

With the increase of transplanting frequency, the upright rate and qualification rate of planting depth showed a downward trend. The rate of missing seedlings, the leakage rate, the injury rate of seedlings and the variation coefficient of plant spacing showed an upward trend. Especially when the planting frequency was increased from 75-90 plants/min, the upright rate and qualification rate of planting depth decreased greatly. The rate of missing seedlings, the leakage rate, the injury rate of seedlings increased greatly.

The standard deviation of each test index in this test ranged from 0 to $0.69 \%$, which indicates that the machine runs reliably and the operation state was stable. In particular, the variation coefficient of plant spacing varied between $0.037 \%$ and $0.099 \%$, which indicates that the machine had a high transplanting accuracy.

\subsection{Discussion}

The planter was a key part of the semi-automatic transplanter and also a difficult point in the design. In this study, clamp-type planter and slideways were used to achieve the precise release and planting of peony seedlings. The chain drive was used to realize the transplanting of seedlings during rotation. It can be seen from the test results that the designed transfer machine can meet the requirements of transplanting operations for peony seedling. And the transplanting effect was good when the transplanting frequency was $60-75$ plants/min. However, when high-speed transplanting (over 90 plants/min) was performed, the transplanting operation effect was significantly reduced. There were several reasons for this problem:

(1) Increasing the transplanting frequency will shorten the time interval between opening and closing the clamp, and will easily cause seedling rhizome damage. In addition, the short distance between the slideways may cause excessive clamping force. The roots of the peony seedlings were divergent, which can easily cause seedling pinching when transplanted. When the distance between the slideways was too large, the clamping force of the planter was insufficient. Seedlings tend to fall off during the clamping process, causing lodging or missing plants. The key point was to match the distance between the slideways and the design of the putter.

(2) When the transplanting frequency increases, the operation speed of the transplanter was accelerated. Correspondingly, the movement speed of each mechanism of the transplanter was accelerated. When the seedlings were released, excessive clamp speed and acceleration can easily make the horizontal speed of the seedlings too large. Then miss the zero-speed planting point, causing lodging, insufficient planting depth, and unqualified plant spacing. 


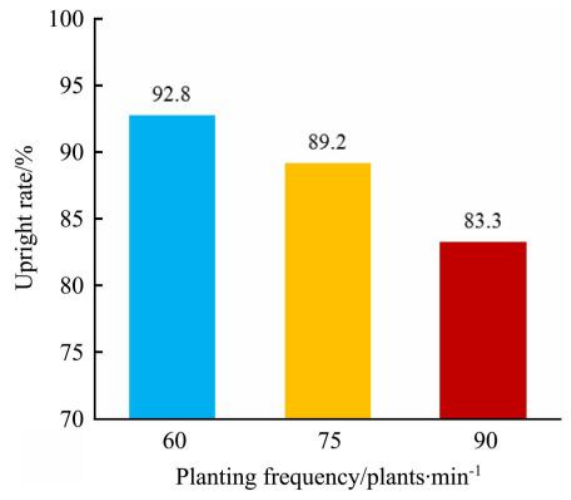

a.

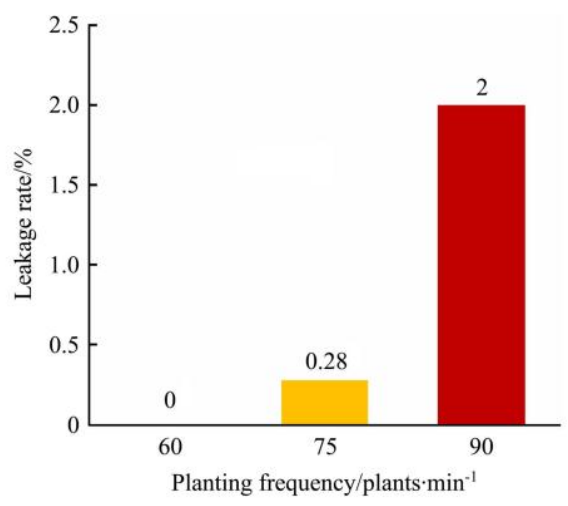

b.

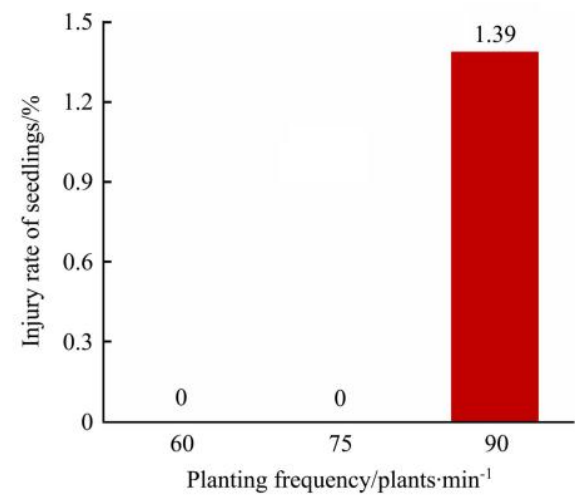

c.

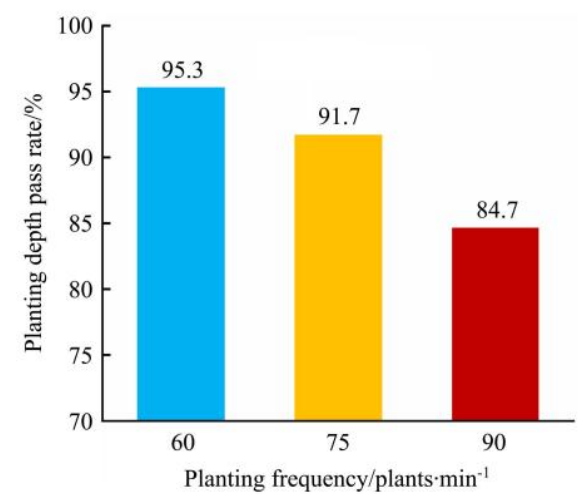

d.

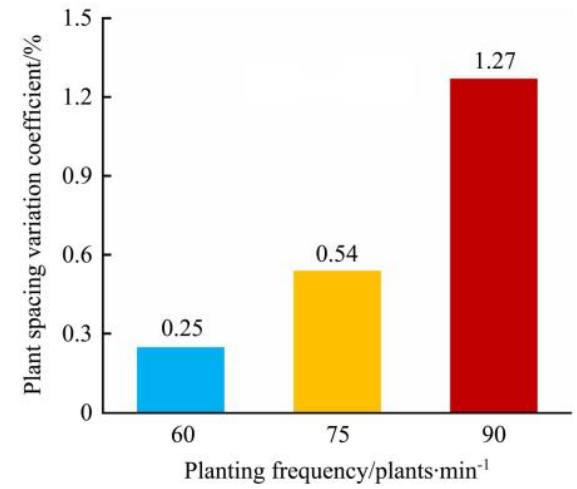

e.

Figure 14 Average of test indexes at different planting frequencies

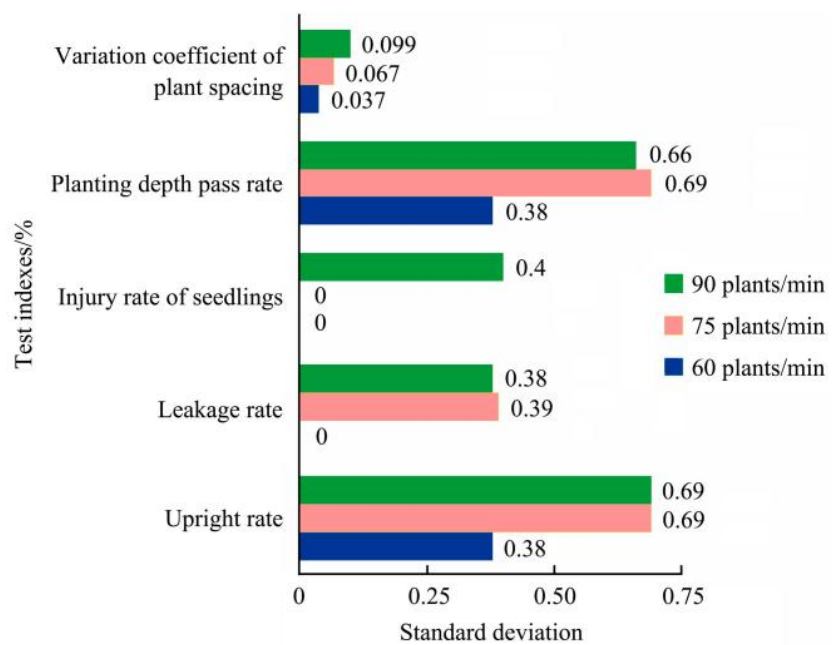

Figure 15 Standard deviation of test indexes at different planting frequencies

(3) Increasing the transplanting frequency makes the rotational inertia of the planter too large. It can change the spatial posture of the peony seedlings after release. As a result, seedlings cannot be planted according to the established trajectory, which may cause problems such as lodging and poor stability of plant spacing.

(4) Peony seedlings had the characteristics of multiple roots. When the seedlings were released, the putter on both sides of the clamp may be involved with the roots, affecting the timing of seedling release and the posture of the seedlings. This problem was not obvious when transplanting at low speed. But when the transplanting speed increased, the process was required to be carried out quickly and smoothly. When the accuracy requirement was high, the influence of unexpected factors on the test results was amplified. As a result, problems such as a reduction in the upright rate, unqualified planting depth and plant spacing were easy to occur.

(5) When the frequency of transplanting was increased, correspondingly, the operator fed the seedlings at the same speed. Repeated feeding of seedlings at high frequency can easily cause operator fatigue. This could cause improper feeding time and improper seedling position or missing seedling, and then affect the planting depth, upright rate and leakage rate.

(6) The seedling clamping point does not coincide with the center of gravity of the seedling. The moment the seedlings were planted after they were released, they should remain relatively still with the ground. Otherwise, it will directly affect the seedling planting depth and the state of the root system after covering the soil. This will lead to problems such as unqualified planting depth, reduced upright rate, etc.

For the above reasons, the following methods could be used to improve the working quality of the transplanting machine. For example, set the seedling release advance or adjust the slideways distance. Match the positional relationship between the opener, the soil compaction wheel and the planting point. At the same time, install springs and balance weights at the places where the mechanism's inertia was large to reduce the inertia force. Therefore, the high-speed transplanting performance of the oil peony transplanter will be further improved.

\section{Conclusions}

(1) A semi-automatic transplanting machine for oil peony seedlings was designed. It was manually picked and fed. The chain-clamp type planting mechanism was used for seedlings transport and transplanting operations. The opening and closing of the planter were jointly controlled by the putter and the slideways. It can ensure the smooth transportation of seedlings 
and the smooth operation of the mechanisms.

(2) Through the motion analysis of the planting operation process, the key parameters of the planting mechanism and the slideway were determined. In order to meet the requirements of stable transporting, timely releasing and planting, and to meet its physical and mechanical characteristics, with the goal of preventing injury and missing seedlings, the effective length of the clamp was determined to be $L_{1}=235 \mathrm{~mm}$ and the length adjustment range was $235-285 \mathrm{~mm}$. The radius of planting sprocket was $R_{1}=42 \mathrm{~mm}$, $R_{2}=80 \mathrm{~mm}$. It was determined that the initial angle difference between the two ends of the putter $\theta=13^{\circ}$, the angle between the two extreme positions was $\beta=37^{\circ}$, the height ratio of the putter was $\varepsilon=2$. The distance between the slideways was $S=35 \mathrm{~mm}$. And the radius at the entrance of the slideways was $R_{0}=80 \mathrm{~mm}$.

(3) The results of the whole machine test showed that: when the transplanting frequency was 60-75 plants/min, the transplanting quality and transplanting accuracy were good. At this time, the upright rate was $89.2 \%-92.8 \%$, the leakage rate was $0-0.28 \%$, the injury rate was 0 , the qualified rate of planting depth was $91.7 \%-95.3 \%$, and the variation coefficient of plant spacing was $0.25 \%-0.54 \%$.

\section{Acknowledgements}

This work was financially supported by the National Key Research and Development Program of China Project (No.2016YFD0700100), the Henan Provincial Department of Science and Technology Research Project (No.182102110044), the Key Research and Development Program of Guangdong Province (No.2019B020 222004), and the Innovation Scientists and Technicians Talent Projects of Henan Provincial Department of Education (No.19HASTIT021).

\section{[References]}

[1] Pei X H, Cao R, Guan B L, Liu S B, Lu J J. Status and existing problems of oil peony industry in Liaoning Province. Liaoning Agricultural Sciences, 2019; 2: 72-73. (in Chinese)

[2] Chen F Z, Liu Y M, Li B X, Chen Z W, Li X L, Tong X M. The status quo and development countermeasures of the standardized system of oil peony. Hubei Agricultural Sciences, 2019; 58(20): 109-112, 120. (in Chinese)

[3] Li X L, Chen F Z, Tong X M, Chen Z W, Chen Z, Yang S K, et al. The low-yield reasons and key cultivation techniques for increasing yield of oil peony in Hubei Province. Hubei Agricultural Sciences, 2019; 58(16): 84-88, 195. (in Chinese)

[4] Tian F Z. Research overview and development direction of peony seed oil in health industry. Agriculture and Technology, 2019; 39(23): 9-15. (in Chinese)

[5] Zhao H J, Wei F, Fu M R, Chao Zhen. Effects of processing technology on fatty acid composition, physical and chemical properties and antioxidant capacity of peony seed oil. Journal of Food Safety and Quality Inspection, 2019; 10(24): 8377-8381. (in Chinese)

[6] Yuan Q Q, Liu W Y. Research progress on nutrition and functional components in peony seeds. Science and Technology of Food Industry, 2019; 40(17): 333-339. (in Chinese)
[7] Chang X, Sheng Y S, Zhang J J, Ren A Z, Zhao P B, Li D C. Research progress on oil peony cultivation and seed oil processing. Journal of Anhui Agricultural Sciences, 2019; 47(1): 13-16. (in Chinese)

[8] Jin X, Du X W, Yang C H, Ji J T, Dong Z, Yan H. Design and experiment of automatic conveying device for transplanting plug seedlings in vegetables. Transactions of the CSAM, 2016; 47(7): 103-111. (in Chinese)

[9] Xiao M T, Xiao S X, Sun S L, Chen B, Chen S. Research status and development trend of rapeseed bowl seedling transplanting mechanism. Journal of Agricultural Mechanization Research, 2019; 41(12): 1-6. (in Chinese)

[10] Ji J T, Li M Y, Jin X, Pang J, Lv H Z. Experiment on mechanical properties of pepper seedlings based on high-speed and low-loss planting. International Agricultural Engineering Journal, 2017; 26(4): 175-183.

[11] He Y K, Cui W, Li S J, GAO X W, Chen K, Han Z H, et al. Design and experiment of automatic transplanter for dryland pot seedlings. Journal of Agricultural Mechanization Research, 2019; 41(4): 53-57. (in Chinese)

[12] Jin X, Yuan Y W, Ji J T, Zhao K X, Li M Y, Chen K K. Design and implementation of anti-leakage planting system for transplanting machine based on fuzzy information. Computers and Electronics in Agriculture, 2020; 169: 105204. doi: https://doi.org/10.1016/j.compag.2019.105204.

[13] Xia G B, Han C J, Guo H, Zhang J, Ge P, Xu Y. Research status and development trends of key components of fully automatic transplanting machinery. Journal of Agricultural Mechanization Research, 2019; 41(2): 1-7, 14. (in Chinese)

[14] Chen D J, Hou J L, Shi G Y, Li T H, Zhang Y S, Chang J M. Analysis on the status quo of domestic dryland transplanting machine technology. China Agricultural Mechanical News, 2018; 39(7): 98-102. (in Chinese)

[15] Jin X, Chen K K, Ji J T, Pang J, Du X W, Ma H. Intelligent vibration detection and control system of agricultural machinery engine. Measurement, 2019; 145: 503-510.

[16] Chen Q, Yun J, Chen Y S, Hu Y, Gao Q S. Development status of vegetable transplanting machinery at home and abroad. Vegetables, 2016 8: 76-79. (in Chinese)

[17] Ji J T, Sun J W, Jin X, Li M Y, Du X W. Development of a PVDF sensor for potted seedling clamping force of vegetable transplanting. Int J Agric \& Biol Eng, 2019; 12(5): 111-117.

[18] Yi S J, Liu Y F, Wang C, Tao G X, Liu H Y, Wang R H. Experimenta study on the performance of bowl-tray rice precision seeder. Int J Agric \& Biol Eng, 2014; 7(1): 17-25.

[19] Feng Q C, Zhao C J, Jiang K, Fan P F, Wang X. Design and test of tray-seedling sorting transplanter. Int J Agric \& Biol Eng, 2015; 8(2): 14-20.

[20] Jin, X, Li D Y, Ma H, Ji J T, Zhao K X, Pang, J. Development of single row automatic transplanting device for potted vegetable seedlings. Int $\mathrm{J}$ Agric \& Biol Eng, 2018; 11(3): 67-75.

[21] Han C J, Xu Y, Zhang J, You J, Guo H. Design and Experiment of Semi-Automatic Compressing Substrate-type Watermelon Bowl Seedling Transplanter. Transactions of the CSAE, 2018; 34(13): 54-61. (in Chinese)

[22] Wang Y W, He Z L, Wang J, Wu C Y, Yu G H, Tang Y H. Experimental test of automatic transplanting machine for dryland vegetable bowl seedling. Transactions of the CSAE, 2018; 34(3): 19-25. (in Chinese)

[23] Li H, Cao W B, Li S F, Liu J D, Chen B B, Ma X X. Development of 2ZXM-2 automatic vegetable plug seedling transplanting machine. Transactions of the CSAE, 2017; 33(15): 23-33. (in Chinese)

[24] Han L H, Mao H P, Hu J P, Xu J Y, Zhao Z R Ma G X. Design and experiment of automatic transplanter for greenhouse plug seedlings. Transactions of the CSAM, 2016; 47(11): 59-67. (in Chinese)

[25] Cui Z C, Chen Y S, Guan C S, Yang Y T, Gao Q S, Zhao G D Experimental research on transplanting machine of substrate bulk vegetable. Journal of Agricultural Mechanization Research, 2019; 41(10): 158-161,168. (in Chinese) 